\title{
Comparison of distance covered in paddle in the serve team according to performance level
}

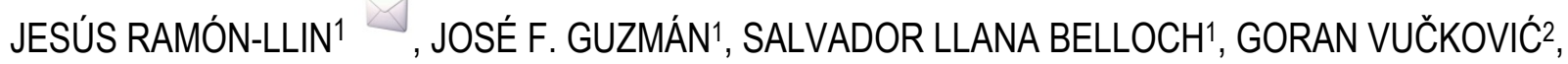 \\ NIC JAMES ${ }^{3}$ \\ ${ }^{1}$ Faculty of Physical Activity and Sport Sciences, University of Valencia, Spain \\ ${ }^{2}$ Faculty of Sport, University of Ljubljana, Ljubljana, Slovenia \\ ${ }^{3}$ Sport Institute, University of Middlesex, London, England
}

\begin{abstract}
Ramón-Llin J, Guzmán J, Llana S, Vučković G, James N. Comparison of distance covered in paddle in the serve team according to performance level. J. Hum. Sport Exerc. Vol. 8, No. Proc3, pp. S738-S742, 2013. Although paddle is the second most practiced sport in Spain, the scientific knowledge about the players' work-load is still very low. The serve is a critical situation because the team has the opportunity to start the point attacking by approaching the net straight after the serve. However, the distance covered by the serve team still has not been studied in pádel. OBJECTIVE: This study aimed to analyse the distance covered by the serve team according performance level. It was hypothesized that the server would cover more distance than his partner due to the approach to the net after the serve. Moreover, it also was hypothesized that the difference between serve and partner would be greater to the highest performance level. METHODS: We analysed a sample of 1500 points divided in 3 levels of performance (high, medium and recreational, 500 points each one). We compared the distance covered between the server and his partner in 500 hundred points to each level performance. The points were taken from 14 matches (4 of high, 5 of medium and 5 of recreational level). SAGIT software (Vučković et al., 2002) was used to get the data. Analyses were performed with Microsoft Excel and SPSS 20.0. RESULTS: Wilcoxon Signed Ranks test were performed. At high level, the median of distance covered by the server was of 10.7 meters, significantly greater than the 7.5 meters covered by the partner of the server $(Z=-11.7 ; p<.001)$. At medium level, the median of distance covered by the server was of 9.2 meters, also significantly greater than the 6.6 meters covered by the partner of the server $(Z=-12.1 ; p<.001)$. At recreational level, the median of distance covered by the server was of 8.4 meters, also significantly greater than the 6.1 meters covered by the partner of the server $(Z=-10,2 ; p<.001)$. DISCUSION: Independently of the level performance, the player serving covered more distance than his partner. These results have implications to training and tactics used in games, as the decision about what player is going to start serving each set, the skill fullest or the toughest. Key words: ACTIVITY PATTERNS, MOVEMENT ANALYSIS, WORKRATE.
\end{abstract}

\footnotetext{
Corresponding author. Faculty of Physical Activity and Sport Sciences. University of Valencia. Spain. C/ Gascó Oliag n³, CP 46010. Valencia.

E-mail: jeramas@hotmail.com

Performance Analysis Workshop, 2 - 5 April 2013, Alicante, Spain

JOURNAL OF HUMAN SPORT \& EXERCISE ISSN 1988-5202

(c) Faculty of Education. University of Alicante

doi:10.4100/jhse.2013.8.Proc3.20
} 


\section{INTRODUCTION}

Paddle, was invented in México 45 years ago. It has progressed a lot in competition and recreational levels. In 2013 it will have a 15 million euros circuit in man modality known as World Paddle Tour. In fact, paddle has become the second most practiced sport in Spain, behind soccer (Ciria et al., 2012). Its success may be due to that it is very easy to learn, it has a social component and it is very profitable according the economical aspects (Almonacid, 2012).

Quantify the loads related to covered distance in training and games is a hard work to researchers but results are very useful to coaches (O'Donoghue, 2010). Movement patterns during the serve has been analysed in sports as tennis (Hughes \& Moore, 1998), and discussed in squash when winning and losing players were compared (Vučković et al., 2004). Vučković et al., (2004) discussed than winners covered more distance than losers due to the extra number of movements to the $T$ area following a serve made by the winners, which was a consequence of them serving more often than the losers.

Serve in paddle is very similar to modality doubles tennis, where player serving approaching to the net after the serve while the partner is already waiting close to the net. Nevertheless, meanwhile the position of the partner in tennis can be turned back for the second serve, in paddle the position is kept close to the net. Thus, it may be expected more differences between server and partner in paddle than in tennis.

As movement patterns may change according to performance level, in this study this variable was controlled analysing three performance levels (high, medium, and recreational). Thus the objective of the present study was to compare the distance covered by the player serving and his partner during the point (rally) at three performance levels. It was hypothesised than the player serving would cover more distance than his partner, and that this tendency would be kept in the three levels, although it could be greater to higher level due to in recreational level sometimes the player serving doesn't approach to net because he is too tired to go fast to the net.

\section{MATERIAL AND METHODS}

\section{Design}

500 points of each level (high, medium and recreational) were got from 5,4 and 5 matches respectively. Players age (years) were $M=33,3 ; S D=6,3$ for high, $M=32,2 ; S D=5,5$ for medium; and $M=34,2 ; S D=$ 7,8 for recreational level. All players signed to accept be recorded for research use. In the 500 points analised for each level the ball continued being played after the serve shot.

\section{Procedure}

All matches were recorded with 2 fixed digital video cameras (BOSCH DINION IP 455, Germany) capturing images at $25 \mathrm{~Hz}$. Each camera covered a half side of the paddle court with its maximum angle because they were fixed to the ceiling at 7 meters over the court. Digital images were processed by the SAGIT tracking system (Vučković et al., 2002). Final data were stored using Microsoft Excel software.

\section{Statistical analysis}

Data were filtered to analyse distance covered it only when the ball was in play. Moreover distance was analysed per point (rally), as has been suggested when the differences between games or sets may be very small (Vučković \& James, 2010). Data analyses were performed using the SPSS 20.0 statistical package. The data didn't have normal distribution so a non-parametric Wilcoxon signed ranks test was 
used to compare the distance covered by the player serving and his partner. Statistical significance was accepted at $p<.05$.

\section{RESULTS}

At high level, the median of distance covered by the server was of 10.7 meters, significantly greater than the 7.5 meters covered by the partner of the server $(Z=-11.7 ; p<.001)$. From 500 points, in 381 the player serving covered more distance than his partner what means a $76 \%$ of the points. The median of distance covered by the player serving was a $45 \%$ higher than his partner.

At medium level, the median of distance covered by the server was of 9.2 meters, also significantly greater than the 6.6 meters covered by the partner of the server $(Z=-12.1 ; p<.001)$.). From 500 points, in 387 the player serving covered more distance than his partner what means a $77 \%$ of the points. The median of distance covered by the player serving was a $39 \%$ higher than his partner.

Table 1. Descriptive data according player and level, and significance of differences between players in each level

\begin{tabular}{|c|c|c|c|c|c|c|c|c|c|}
\hline & \multicolumn{3}{|c|}{ High level } & \multicolumn{3}{|c|}{ Medium level } & \multicolumn{3}{|c|}{ Recreational level } \\
\hline & $\begin{array}{l}\text { Player } \\
\text { serving }\end{array}$ & Partner & Z (Sig.) & $\begin{array}{l}\text { Player } \\
\text { serving }\end{array}$ & Partner & Z (Sig.) & $\begin{array}{l}\text { Player } \\
\text { serving }\end{array}$ & Partner & Z (Sig.) \\
\hline Mean & 14.05 & 11.15 & $-11.7\left(^{*}\right)$ & 12.13 & 9.7 & $-12.1\left(^{*}\right)$ & 10.51 & 8.56 & $-10.2\left(^{*}\right)$ \\
\hline Std. Error & .47 & .47 & & .42 & .42 & & & .3519 & \\
\hline $\begin{array}{l}\text { Confidence Lower Bound } \\
\text { Intervalfor }\end{array}$ & 13.14 & 10.21 & & 11.30 & 8.87 & & 9.81 & 7.87 & \\
\hline Upper Bound & 14.97 & 12.09 & & 12.97 & 10.53 & & 11.22 & 9.25 & \\
\hline $5 \%$ Trimmed Mean & 12.93 & 10.01 & & 11.07 & 8.69 & & 9.73 & 7.72 & \\
\hline Median & 10.73 & 7.45 & & 9.20 & 6.62 & & 8.44 & 6.11 & \\
\hline Variance. & 108.20 & 112.99 & & 90.22 & 89.25 & & 64.16 & 61.91 & \\
\hline Stcd Deviation & 10.40 & 10.633 & & 9.50 & 9.45 & & 8.01 & 7.87 & \\
\hline Minimum & 1.26 & .26 & & .09 & .00 & & -5.55 & -5.72 & \\
\hline Maximum & 74.30 & 56.24 & & 66.42 & 68.77 & & 50.87 & 58.21 & \\
\hline Range & 73.04 & 55.98 & & 66.32 & 68.77 & & 56.42 & 63.93 & \\
\hline Interquartile Range & 11.07 & 12.31 & & 9.62 & 10.15 & & 9.10 & 9.03 & \\
\hline Skewness & 1.92 & 1.58 & & 2.02 & 1.92 & & 1.76 & 1.93 & \\
\hline Kurtosis & 5.08 & 2.47 & & 5.54 & 5.31 & & 4.40 & 5.52 & \\
\hline
\end{tabular}

At recreational level, the median of distance covered by the server was of 8.4 meters, also significantly greater than the 6.1 meters covered by the partner of the server $(Z=-10,2 ; p<.001)$. From 500 points, in 358 the player serving covered more distance than his partner, what means a $72 \%$ of the points. The median of distance covered by the player serving was a $38 \%$ higher than his partner.

In summary, we found statistical differences in all levels, with higher distance covered by the player serving. The differences between median ranged from 38\% higher for the player serving at recreational level to $45 \%$ at high level. The percentage of points were the player serving covered more distance than his partner, ranged from $72 \%$ at recreational level to $77 \%$ at medium level. 


\section{DISCUSSION}

As we hypothesized the player serving covered more distance than his partner. In more than the $70 \%$ of the points the player serving covered more distance than his partner, and in medium and high level this percentage reached 3 of each 4 points. The difference in median of distance covered were almost $40 \%$ higher in medium and recreational level, and $45 \%$ at high level. Coaches teach their pupils to go to the net after the serve, because in paddle the players in the net are attacking to the players back who are defending (Almonacid, 2012). So player serving covered more distance what probably means that there are a movement pattern like approach to the net as fast as possible after the serve. Thus, the tactics used by the serving player adjusted to the "serve and volley" tactics described in tennis (Hughes \& Moore, 1998).

Percentages of differences were higher at medium and higher level in comparison to recreational level. The lower differences at recreational level, when player serving is tired he probably will not approach to the net after the serve. The differences between high and medium level could be due to in high level the tactic used for the serve is called "Australian serve" where each player start the point attacking or defending in the same position which can be right or left on the court. Probably "Australian tactic" requires more distance covered in the approach to the net than" normal tactic" (see figure 1). Coaches teach to the team in high level to play always "Australian tactic".

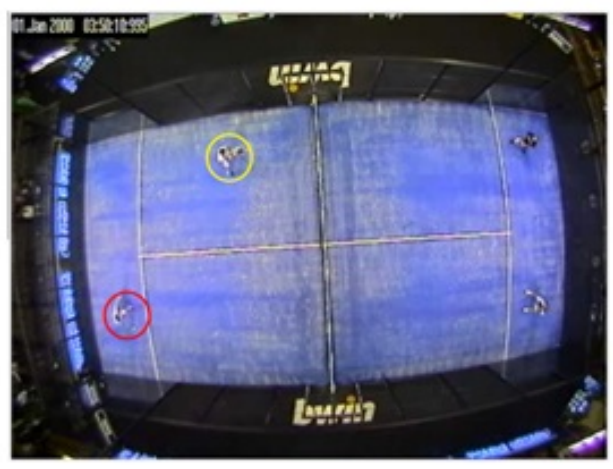

(a)

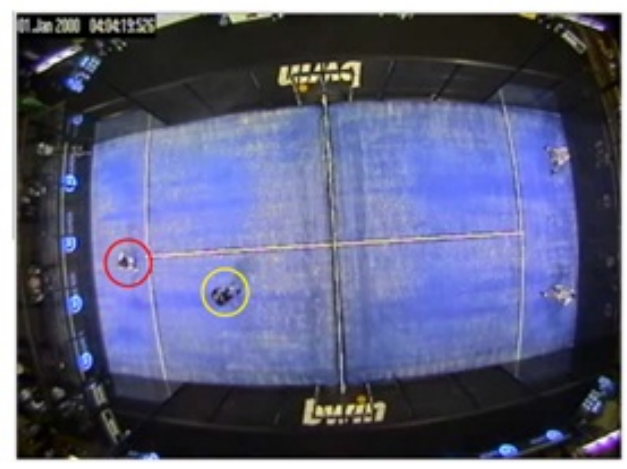

(b)

Figure 1. "Normal serve tactic" (a), and "australian serve tactic" (b), when the player serving (red color) serves to deuce side

These results may have new implications to training and game tactics. Usually coaches indicate their players that the skill fullest or the more aggressive with the serve must start serving each set. Nevertheless, coaches should also consider that in three set matches fatigue is an important variable. Thus it may be decided in third set that the player who start serving should be the less tired, although he was the less skilled. In the same way, sometimes coaches advice their players to load the game to the player more tired, but it is not easy to know who is. Results of this study suggest that the player more tired will probably be the one who has need more number of points to complete his serve game or who has served in a higher number of games.

In order to deepen in this question, future research should count the number of approaches to the net of the serving player after the serve shot, previously to finish the rally. Also would be interesting to control the tactic used for the serve. 


\section{CONCLUSIONS}

This is the first study about the paddle serve requeriments in terms of distance covered. The main finding was that the player serving covered more distance than his partner at different performance levels, although percentages indicated a tendency to run more at highest levels. Coaches should consider strategies to minimize or take advantage of this overeffort and take it into account for the training planification and game tactics.

\section{REFERENCES}

1. ALMONACID B. Perfil de juego en pádel de alto nivel. Jaen: University of Jaen. 2012.

2. CIRIA C, GONZALEZ M, RAMOS A, MILLÁN L. 2012. El pádel de la jet set a deporte popular. On line in www.dragondigital.es. Querie in 20-03-2012.

3. HUGHES M, MOORE P. Movement analysis of elite level male "serve and volley" tennis players. In: Hughes M, Maynard I, Lees A, Reilly T. (Eds.). Science and Racket Sports II. London: Routledge. 1998.

4. O'DONOGHUE P. Performance Analysis Research. In: O'Donoghue P. (Ed.). Research methods for sport performance analysis. London: Routledge. 2010.

5. RAMON-LLIN J,GUZMÁN JF, MARTINEZ-GALLEGO R, VUCKOVIC G, JAMES N. Distance covered and velocity of movements during a closely contested pro tour match. In: Book of Proceedings of World Congress Performance Analysis of Sport IX. London. 2012.

6. VUČKOVIĆ G, DEZMAN B, ERCULJ F, KOVACIC S, PERS J. Computer tracking of players at squash matches. Acta kinesiol. 2002; 7: 216-220.

7. VUČKOVIĆ G, DEZMAN B, ERCULJ F, KOVACIC S, PERS J. Differences between the winning and the losing players in a squash game in terms of distance covered. In: Lees A, Khan JF, Maynard IW. (Eds.). Science and Racket Sports III. London: Routledge. 2004. Pp. 202-207.

8. VUČKOVIĆ G, JAMES N. The distance covered by winning and losing players in elite squash matches. Kinesiologia Slovenica. 2010; 16(1-2): 44-50. 